\title{
PENINGKATAN KEMAMPUAN PEMAHAMAN KONSEP IPA SISWA DAN PENGELOLAAN PEMBELAJARAN GURU DENGAN MENERAPKAN MODEL PEMBELAJARAN BERBASIS MASALAH
}

\author{
Nurhasana Siregar \\ Fakultas Ilmu Pendidikan dan Keguruan, Universitas Graha Nusantara \\ email: nurhasana.siregar08@gmail.com
}

\begin{abstract}
Abstract: This action research aims to describe the understanding of students' science concepts and describe the teacher's ability to manage learning on the actual problems of learning in the classroom by applying problem-based learning models. The research subjects were students of class VII-4 totaling 44 people and 1 science teacher. This classroom action research is carried out in two cycles, each of which consists of the stages of planning, implementing actions, observation, and reflection. The results showed that the ability of students to understand the concept in the first cycle was $59.09 \%$, and in the second cycle there was an increase with a percentage of $86.36 \%$. While the ability of teachers in the first cycle the average score of 3.1 and in the second cycle there was an improvement in learning practices so that an increase in the average score (3.8).
\end{abstract}

Keywods: concept understanding, management of learning, problem based learning.

\begin{abstract}
Abstrak
Penelitian ini bertujuan untuk mendeskripsikan pemahaman konsep IPA siswa dan mendeskripsikan kemampuan guru dalam pengelolaan pembelajaran terhadap permasalahan aktual pembelajaran di kelas dengan menerapkan model pembelajaran berbasis masalah. Subjek penelitian adalah siswa kelas VII-4 yang berjumlah 44 orang dan 1 guru IPA. Penelitian tindakan kelas ini dilakukan dengan dua siklus, yang mana setiap siklusnya terdiri atas tahapan perencanaan, implementasi tindakan, observasi, dan refleksi. Hasil penelitian menunjukkan bahwa kemampuan pemahaman konsep siswa pada siklus I sebesar 59,09 \%, dan pada siklus II terjadi peningkatan dengan persentasi pencapaian $86,36 \%$. Sedangkan kemampuan guru pada siklus I rata-rata skor sebesar 3,1 dan pada siklus II terjadi perbaikan praktek pembelajarannya sehingga terjadi peningkatan rata-rata skornya $(3,8)$.
\end{abstract}

Kata Kunci: pemahaman konsep, pengelolaan pembelajaran, pembelajaran berbasis masalah.

\section{PENDAHULUAN}

Salah satu tujuan pembelajaran IPA di jenjang SMP adalah siswa menguasai konsep IPA melalui penemuan konsep dengan menggunakan pendekatan ilmiah. Hal ini sesuai dengan anjuran sistem pembelajaran sekarang yaitu menekankan pendekatan ilmiah. Pendekatan itu, guru harus menyajikan pembelajaran yang dapat meningkatkan rasa keingintahuan (Foster a sense of wonder), meningkatkan keterampilan mengamati (Encourage observation), melakukan analisis (Push for analysis) dan berkomunikasi (Require communication) (Markham, 2003).

Pendekatan pembelajaran yang dianjurkan tersebut masih bertolak belakang dengan dilapangan. Pembelajaran IPA di sekolah masih dominan menggunakan pembelajaran berpusat pada guru (teacher-centered) seperti metode ceramah. Dalam pembelajaran ini siswa hanya mendengarkan penjelasan dari guru, memberikan konsep secara langsung, menjawab pertanyaan dan mengerjakan tugas. Proses 
pembelajaran seperti ini dapat mengakibatkan kejenuhan pada siswa untuk belajar IPA, pelajaran terkesan monoton dan membosankan. Untuk mengatasi permasalahan ini, guru harusnya lebih mengutamakan keaktifan siswa terlibat langsung dalam proses pembelajaran yang akan mengarahkan kepada pembentukan pengetahuan mereka sendiri atau membangun konsepnya sendiri. Oleh karena itu dibutuhkan guru melakukan usaha untuk meningkatkan kemampuannya dalam pengelolaan pembelajaran agar tujuan pembelajaran tercapai. Guru di kelas hanya berperan sebagai fasilitator dalam pembelajaran.

Berdasarkan studi pendahuluan yang telah dilaksanakan, ditemukan bahwa hasil tes pemahaman konsep kelajuan dan kecepatan yang diberikan kepada siswa kelas VIII sangat rendah, secara klasikal 16,67 \% siswa yang bernilai sedang dan siswa yg bernilai rendah sebesar 83,33\%, dan pembelajaran IPA yang diterapkan guru masih menghapalkan konsep. Seharusnya untuk memahami konsep itu diperlukan melalui serangkaian proses pengalaman langsung yang mengutamakan aktivitas siswa untuk memahami konsep.

Salah satu upaya yang dapat dilakukan agar siswa memiliki kemampuan pemahaman konsep IPA yaitu dengan menerapkan pembelajaran berbasis masalah (PBM). Pada pembelajaran berbasis masalah menekankan siswa untuk aktif mengkontruksi konsep-konsep fisika dari masalah yang diberikan, juga mampu menjelaskan konsep-konsep yang diperolehnya serta menerapkan konsep tersebut ke dalam penyelesaian masalah. Pembelajaran berbasis masalah adalah metode pembelajaran berdasarkan prinsip yang menggunakan masalah konstekstual sebagai titik awal untuk memperoleh pengetahuan baru dan memadukannya dengan pengetahuan sebelumnya (Barrows, 2002). Selain itu Azman menyatakan PBM adalah metode pembelajaran yang berpusat pada peserta didik yang bertujuan untuk mengembangkan katerampilan pemecahan masalah, belajar mandiri yang menjadi suatu kebiasaan dan keterampilan dalam kerja tim (Azman, 2012).

Diharapkan dengan munculnya pemahaman konsep IPA siswa, dapat memberikan motivasi belajar IPA, menumbuhkan rasa percaya diri siswa terhadap potensi yang dimilikinya dan akan meningkatkan hasil belajar IPA siswa serta dapat mengaplikasikan konsep IPA dalam kehidupan sehari-hari. Dengan demikian, penilitian ini akan membahas peningkatan kemampuan pemahaaman konsep IPA siswa dan kemampuan guru dalam pengelolaan pembelajaran dengan menerapkan pembelajaran berbasis masalah.

\section{METODE PENELITIAN}

Dalam mewujudkan peningkatan kemampuan pemahaman konsep siswa dibutuhkan suatu tindakan untuk memperbaiki strategi pembelajaran oleh guru secara regular agar mutu pembelajaran yang terjadi di kelas semakin meningkat. Oleh sebab itu metode penelitian yang digunakan adalah penelitian tindakan kelas (PTK). Penelitian ini dilaksanakan di MTs Negeri 1 Padangsidimpuan. PTK merupakan penelitian melalui proses pengkajian bersiklus yang terdiri atas empat tahapan, yaitu planning, action, observation dan reflection (Gambar 1) (Asmani, 2011).

Teknik pengumpulan data pemahaman konsep IPA siswa pada materi gerak lurus menggunakan tes tertulis pemahaman konsep, dan untuk mendeskripsikan daya serap kemampuan pemahaman konsep siswa yakni menuliskan konsep, memberikan contoh dan bukan contoh konsep, dan menerapkan konsep dalam menyelesaikan masalah, dikatakan tuntas dengan kriteria kemampuan pemahaman konsepnya, jika:

$\leq 65 \%$; belum mampu memahami konsep

$\geq 65 \%$; telah mampu memahami konsep. 
Selanjutnya kriteria suatu kelas dikatakan tuntas secara klasikal, jika : $\leq 80 \%$ kelas belum tuntas dalam memahami konsep $\geq 80 \%$ kelas telah tuntas dalam memahami konsep.

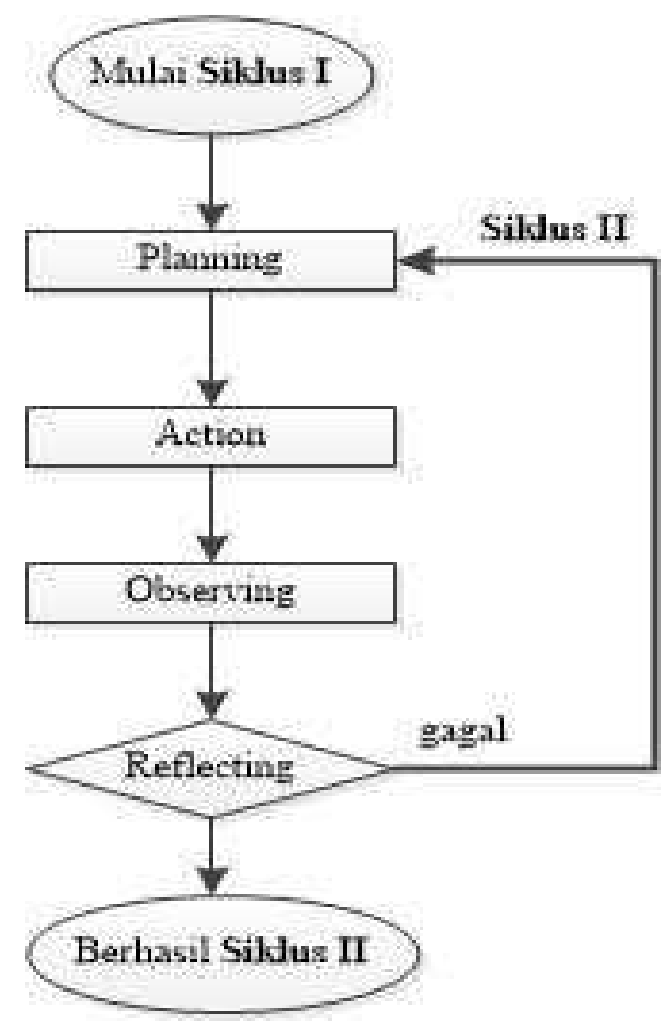

\section{Gambar 1. Diagram alir prosedur penelitian}

Pengumpulan data pengelolaan pembelajaran guru dengan menggunakan pemberian skor lembar observasi dengan kriteria hasil pengamatannya $N$ :

$1,0 \leq N<2,0$ : kurang baik

$2,0 \leq N<3,0$ : cukup baik

$3,0 \leq N<3,5$ : baik

$3,5 \leq N \leq 4$ : sangat baik

\section{HASIL DAN PEMBAHASAN}

Hasil pemahaman konsep siswa secara klasikal pada siklus I yaitu sebesar $59,09 \%$ yakni terdapat 26 siswa yang tuntas dari 44 siswa. Dengan demikian dapat dikatakan kelas tersebut belum berhasil dalam memahami konsep karena masih dibawah $80 \%$. Jumlah pemahaman konsep IPA siswa dikategori sangat rendah terdapat 8 siswa dan kategori sangat tinggi 3 siswa. Sehingga dibutuhkan tindakan selanjutnya pada siklus II agar terjadi peningkatan kemampuan pemahaman konsep IPA siswa pada katekogi sangat tinggi dan penurunan jumlah siswa pada kategori penilaian sangat rendah. Pada siklus II terdapat 86,36\% ketuntasan secara kalsikal dengan 38 siswa, dan kategori pemahaman konsep siswa sangat tinggi terjadi peningkatan (6 siswa) dan terjadi penurunan jumlah siswa dengan penilaian sangat rendah ( 2 siswa), maka pada siklus II telah berhasil. Lebih jelasnya deskripsi tes pemahaman konsep IPA siswa ditunjukkan pada Tabel 1. 
Tabel 1. Deskripsi Hasil Tes Pemahaman Konsep IPA Siswa

\begin{tabular}{|c|c|c|c|c|c|}
\hline \multirow{2}{*}{ Penilaian } & \multirow{2}{*}{$\begin{array}{c}\text { Kategori } \\
\text { Penilaian }\end{array}$} & $\begin{array}{c}\text { Jumlah } \\
\text { Siswa }\end{array}$ & $\begin{array}{c}\text { Persentase Jumlah } \\
\text { Siswa (\%) }\end{array}$ & $\begin{array}{c}\text { Jumlah } \\
\text { Siswa }\end{array}$ & $\begin{array}{c}\text { Persentase Jumlah } \\
\text { Siswa (\%) }\end{array}$ \\
\hline $90-100$ & Sangat tinggi & 3 & 6,82 & 6 & 13,64 \\
\hline $80-89$ & Tinggi & 9 & 20,45 & 14 & 31,82 \\
\hline $65-79$ & Sedang & 14 & 31,82 & 18 & 40,91 \\
\hline $55-64$ & Rendah & 10 & 22,73 & 4 & 9,09 \\
\hline $0-54$ & Sangat rendah & 8 & 18,18 & 2 & 4,54 \\
\hline \multicolumn{2}{r}{ Jumlah } & $\mathbf{4 4}$ & $\mathbf{1 0 0}$ & $\mathbf{4 4}$ & $\mathbf{1 0 0}$ \\
\hline
\end{tabular}

Setelah menerapkan pembelajaran berbasis masalah diperoleh bahwa kemampuan pemahaman konsep siswa meningkat secara linear, dapat dilihat pada Gambar 2.

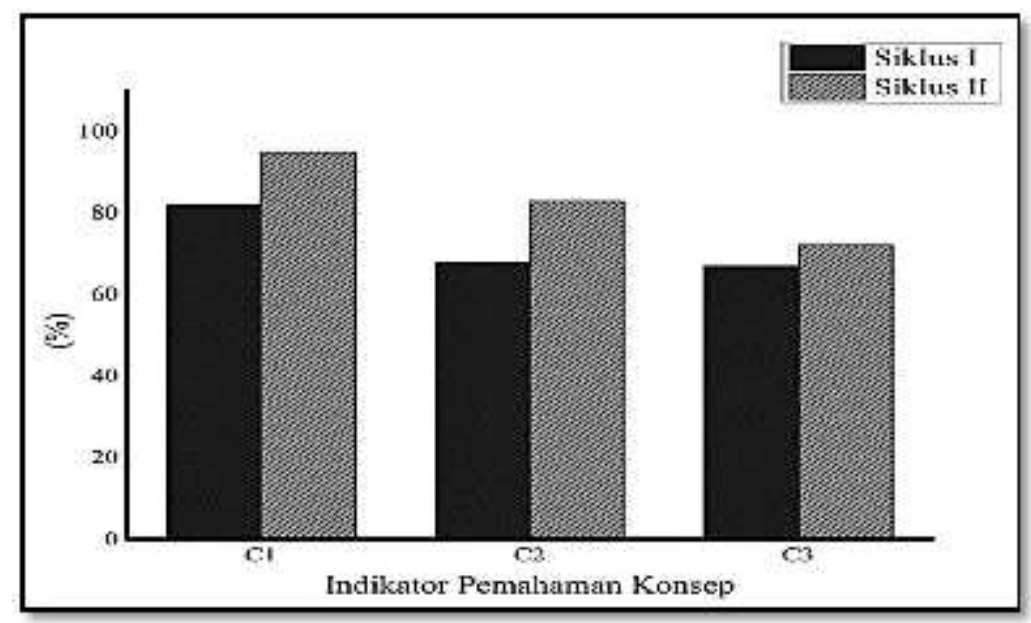

Keterangan :

C1 : Menuliskan konsep

C2 : Memberikan contoh dan bukan contoh konsep

C3 : Menerapkan konsep terhadap pemecahan masalah

\section{Gambar 2. Persentasi kemampuan pemahaman konsep siswa pada siklus I dan} siklus II

Pada siklus I pemahaman konsep siswa C1 kategori tinggi (82\%), C2 kategori sedang (68 \%) dan C3 kategori sedang (67\%), kemudian pada siklus II terjadi peningkatan pemahaman konsep siwa yakni pada C1 kategori sangat tinggi (92\%), C2 kategori tinggi (83\%) dan C3 kategori sedang (73\%). Pada siklus I dan II, peningkatan Indikator pemahaman konsep $\mathrm{C} 1$ dan $\mathrm{C} 2$ secara signifikan kenaikannya, sedangkan C3 sedikit dan masih dikategori sedang karena masih kurangnya siswa dapat mengubungkan pengetahuan dasarnya untuk pemecahan maslah seperti penyelesaian matematisnya, konversi satuan, membaca data, dll. Dalam PBM, siswa belajar bagaimana mengintegrasikan pengetahuan ke dalam analisis mereka dan memecahkan masalah yang dialaminya (Yang, 2012). Selain itu, proses pemecahan masalah dalam PBM mengharuskan siswa untuk mencari bahan dan secara konstan menghubungkan apa yang mereka baca dengan apa yang harus dilakukan dengan informasi (Torp \& Sage, 2002).

Hal ini juga menunjukkan bahwa kemampuan pemahaman konsep IPA siswa masih sulit pada siklus I karna siswa masih terbawa-bawa dengan pembelajaran biasa, dan pada siklus II siswa mulai beradaptasi dengan pemebelajarannya, sehingga lebih mudah menguasai konsep IPA. Siswa mengusai konsep lebih cepat dan efektif karena mereka bekerja kelompok untuk meyelesaikan suatu masalah secara bersama-sama. Ditinjau dari segi pemahaman konsep IPA siswa, maka penelitian ini berhenti pada 
siklus II karena kriteria minimal tiap indikator pemahaman konsepnya diatas $70 \%$ (di atas target).

\section{Pengelolaan Pembelajaran Guru}

Kemampuan guru mengelola pembelajaran melalui model pembelajaran berbasis masalah menunjukkan terjadinya peningkatan kemampuan guru dari siklus I hingga siklus II, dapat dilihat pada Gambar 3.

Pada Gambar 3 menunjukkan bahwa pada siklus I, guru mencapai kategori baik $(3,1)$ dan ini minim di atas kategori cukup baik. Pada pertemuan pertama, bagian kegiatan inti pembelajaran guru merasa kesulitan dalam menajemen waktu pada aspek membimbing investigasi individual maupun kelompok, serta mengembangkan dan menyajikan hasil kerja siswa yang mendapat nilai skor 2,8, ini merupakan skor terendah yang diperoleh. Demikian terjadi karena siswa terbiasa dengan pola pembelajaran konvensional yakni mentrafser konsep IPA secara langsung kepada siswa, sehingga siswa tidak aktif berdiskusi dalam kelompok dan guru harus ekstra dalam membimbing siswa. Ngeow dan Kong menyatakan bahwa PBM dapat sulit diterapkan dalam pengaturan ruang kelas tradisional jika siswa dan guru mengalami kesulitan memahami pembelajaran aktif atau bermakna, dan PBM mengharuskan siswa untuk terlibat dalam strategi pembelajaran aktif dan memperoleh kecondongan belajar mandiri (Ngeow dan Kon, 2001). Kemampuan siswa dan guru untuk terlibat dalam strategi PBM berfungsi sebagai titik fokus untuk keberhasilan belajar (Azman, 2012).

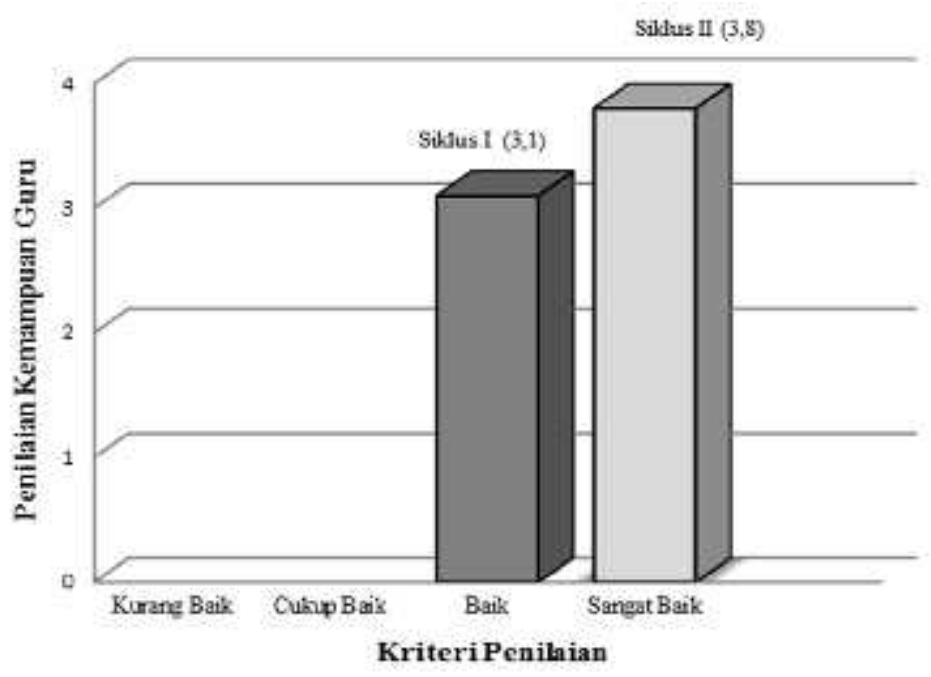

Keterangan :

Kurang baik $\quad: 1,0 \leq \mathrm{N}<2,0$

Cukup baik $\quad: 2,0 \leq \mathrm{N}<3,0$

Baik $\quad: 3,0 \leq \mathrm{N}<3,5$

Sangat Baik $\quad: 3,5 \leq \mathrm{N} \leq 4,0$

\section{Gambar 3. Rerata skor kemampuan Guru dalam pengelolaan pembelajaran}

Dalam proses pembelajaran berbasis masalah, guru memberikan masalah kepada siswa dalam bentuk kelompok, dan mereka mengidentifikasi masalah tersebut dan selanjutnya dapat merumuskan suatu konsep untuk memecahkan masalah itu. Proses pembelajaran ini dapat disebut juga pembelajaran yang menekankan proses berpikir kepada siswa. Guru belum mampu secara maksimal mengelola kegiatan belajar mengajar. Dengan kondisi itu, untuk memperbaiki kelemahan-kelemahan pada siklus I tersebut perlu dilakukan tindakan siklus II dengan upaya untuk memperhatikan waktu yang ditetapkan pada setiap langkah-langkah pembelajaran yang ada dalam RPP dan masalah yang diberikan, agar siswa condong belajar mandiri dan kemampuan siswa bekerja dalam tim meningkat. 
Pada siklus II, ditinjau dari pengelolaan pembelajaran di kelas menunjukkan bahwa guru telah mampu mengatur waktu untuk membimbing investigasi individual maupun kelompok, dan mangatur waktu untuk mengembangkan dan menyajikan hasil kerja siswa karna siswa bisa beradaptasi dengan model pembelajaran yang diterapkan guru sehingga terjadi peningkatan skor yang dipeoleh yaitu 3,6. Kemampuan guru untuk mengelola pembelajaran berada dalam kategori sangat baik dengan nilai ratarata 3,8. Dengan demikian, guru telah mampu meningkatkan kemampuannya dalam mengelola pembelajaran dengan menggunakan model pembelajaran berbasis masalah.

\section{KESIMPULAN}

Model pembelajaran berbasis masalah dapat meningkatkan pemahaman konsep IPA siswa secara klasikal dan kemampuan guru meningkat dalam penggelolaan pembelajaran dengan melaksanakan penelitian tindakan kelas. Dalam hal ini, dapat dilihat hubungan antara meningkatnya pemahaman konsep siswa seiring dengan meningkatnya kemampuan guru dalam mengelola pembelajaran.

\section{DAFTAR PUSTAKA}

Asmani, J. M. (2011). Tips Pintar PTK: Penelitian Tindakan Kelas. Yogyakarta: Penerbit Laksana

Azman, N. Shin, L. K. (2012). Problem-based Learning in English for a Second Language Classroom: Students' Perspectives. The International Journal of Learning. 18 (6): 109-126.

Barrows, H.S. (2002). An overview of authentic problem-based learning (APBM). In Wee, K.N.L. \& Kek, Y. C.M. Authentic problem-based learning: Rewriting business education. Jurong, Singapore: Prentice Hall Asia Pte. Ltd.

Markham, T. (2003). Project-based learning. Edisi Kedua. Novato, CA: Buck Institute for Education.

Ngeow, K., \& Kong, Y. (2001). Learning to learn: Preparing teachers and students for problem-based learning. Retrieved August14, 2008, from ERIC data base.

Torp, L. \& Sage, S. (2002). Problems as possibilities: Problem-based learning for $K$ 16 education. Edisi Kedua. Alexandria, Virginia USA: Association for Supervision and Curriculum Development.

Yang, C. H. (2012). The Concept of Problem-Based Learning, In C. H. Yang (Eds), PBL Teaching Practice-in National Yilan University Experience and Reflection, 2-12. Yilan County: National Yilan University. 